\title{
Correlates of Health Related Quality of Life of Chronic Hepatitis C Children Attending Assiut University Children Hospital.
}

\author{
${ }^{1}$ Hala H. Abu Faddan, ${ }^{1}$ Asmaa Mohamed Ahmed Soliman, ${ }^{2}$ Elham Ahmed Hassan, \\ ${ }^{2}$ Abeer Sharaf El-Din Abd El-Rehim, ${ }^{3}$ Nagla H. Abu Faddan \\ ${ }^{1}$ Public Health and Community Medicine Department; ${ }^{2}$ Department of Tropical Medicine \\ and Gastroenterology; ${ }^{3}$ Pediatric Department Faculty of Medicine, Assiut University \\ Egypt
}

Received: April, $2018 \quad$ Accepted: June, 2018

\begin{abstract}
Background: Egypt is one of the most affected countries by HCV. Health-related quality of life (HRQOL) has become an important outcome measure in patients with chronic liver disease. Data regarding HRQOL among children patients with chronic hepatitis $\mathrm{C}$ (CHC) is lacking. Objectives: To assess the impact of $\mathrm{HCV}$ on health related quality of life of chronic hepatitis $\mathrm{C}$ children and identify risk factors of HRQOL impairment in those children. Methods: A case control study was conducted on 84 Chronic Hepatitis C Children (CHC) and 124 age and sex matched healthy volunteers. HRQOL was assessed by Child Health Questionnaires (CHQ), The CHQ-Parent Report Form (PF50) and CHQChild Report Form (CF87). Risk factors affecting HRQOL of CHC children were assessed by multiple regression analysis. Results: Compared with controls, CHC children had lower HRQOL on all scales of the CHQ. Hypo-albuminemia was significantly associated with impaired physical summary $(\mathrm{PhS})$ of CHQ-Child Form $(\mathrm{P}=0.007)$. However, raised liver enzyme; Aspartate transaminase (ALT) and low platelet count (PLT) were significantly associated with impaired psychosocial summary (PsS) of CHQ-Child Form. Conclusion: CHC children had lower HRQOL than controls. The predictor of impaired Physical HRQOL was hypoalbuminemia while the predictor of impaired psychosocial HRQOL was raised ALT and thrombocytopenia. It is recommended to increase awareness about HCV related issues with special focus on quality of life that is a significant factor when making decisions about hepatitis $\mathrm{C}$ treatment strategies. Medical and social support services should be available to children with HCV.
\end{abstract}

Keywords: Health related Quality of Life, Chronic Hepatitis C Children, Assiut University Children Hospital.

Corresponding author :Asmaa Mohamed Ahmed Soliman Email:asmaasoliman74@yahoo.com

\section{Introduction}

Hepatitis $\mathrm{C}$ virus (HCV) infection is a global health problem and a major cause of morbidity and mortality, the prevalence of $\mathrm{HCV}$ infection in adolescents and children has been $1.8 \%$ $5.8 \%$ in developing countries. ${ }^{1}$

$\mathrm{HCV}$ infection over the pediatric age spectrum differs from infection acquired later in several ways, including, duration of chronic infection, progression of disease, methods of transmission and available treatment. $^{2}$

$\mathrm{HCV}$ infection is extremely underestimated in children and adolescents as in adults. ${ }^{2}$ Only a small percentage can be identified., Prevalence of $\mathrm{HCV}$ infection in Egypt

$\begin{array}{lll}\text { Vol. } 37 & \text { No. } 1 & \text { January }\end{array}$ 
was 3\% in upper Egypt and 9\% in lower Egypt. $^{5}$

Health- related quality of life (HRQOL) is a concept related to person's perception of health status in reference to the culture and value systems in which they live, additionally to their expectations, concerns, goals, and living standards. ${ }^{5}$

$\mathrm{HCV}$ infection is associated with impairment quality of life $(\mathrm{QOL})^{6,7,8,9}$, cognitive performance ${ }^{10,11}$ and psychological functioning. ${ }^{8,12}$ Furthermore, studies reported that lower health-related QOL, deficits in attention, increased levels of anxiety and depression in adults with HCV compared to healthy controls. Very little is known about how HCV affects children along these same parameters. Overall HRQOL in children with chronic hepatitis $\mathrm{C}$ infection using the Peds QLTM 4.0 questionnaire demonstrated decreased emotional/physical functioning, social and school performance in children. ${ }^{5}$

Objective: To assess the impact of HCV on health related quality of life (HRQOL) of CHC children and identify risk factors of HRQOL impairment in those children.

\section{Methods:}

Study Design: a case control study, and normal children were recruited in the study as controls, only to compare their health-related quality of life with those of the studied patients.

Study population: Chronic hepatitis C children. Total coverage of children with chronic HCV infection attending the outpatient clinics of gastroenterology and hepatology unit of Assiut University Children Hospital during the study period, who fulfilled the inclusion criteria, were included in the study.

Inclusion criteria of cases: Patients between 5 and below 18 years old. Chronic hepatitis $\mathrm{C}$ was diagnosed by the presence of positive serologic markers for at least 6 months including anti-HCV antibodies and HCV PCR

Exclusion criteria: Patients with viral coinfection, liver cirrhosis, concomitant chronic diseases, psychiatric illnesses, receiving antiviral drugs or antipsychotic drugs.

Controls (comparison group) were healthy volunteers matched for sex, age, have no chronic diseases, seronegative for HCV infection and had no history of liver diseases.

Eighty-four (84) patients with chronic hepatitis $\mathrm{C}$ and one hundred twenty-four (124) healthy children were included in the study.

The study was conducted between January to April 2016

All participants were subjected to thorough medical history, physical examination for information collection; for example, age, gender, and comorbidities and socioeconomic status. ${ }^{13}$ Abdominal ultrasonography was undertaken. Blood samples were collected (from patients only) for laboratory investigations including complete blood count, liver and kidney function tests

The questionnaire was divided into two parts: (1) Socioeconomic status (age, sex, educational level, employment status of parents, and residence) using Fahmy and El Sherbini scale, 1983. ${ }^{13}$ This scale was used to assess the socio-economic level of the family. The total score ranged from was 23. Those with scores $>19$ were considered of high socioeconomic class, scores 15-19 and < 15 were considered of middle and low socioeconomic classes respectively. (2) Child Health Questionnaires (CHQ) ${ }^{14}$ The CHQ-Parent Report Form(CHQPF50) and the CHQ-Child Report Form (CHQ-CF87).

The CHQ measures generic HRQOL in the physical, psychological, and social domains in children, including physical functioning (PF), bodily pain/discomfort 
(BP), general health (GH), general behavior (BE), mental health (MH), selfesteem (SE); role/social limitations as a result of physical (RP), emotional/behavioral (REB, PF50), emotional (RE), and behavioral (RB) problems (CF87),; and the impact on parental time (PT), parental emotion (PE), family activities (FA), Family Cohesion (FC), and Change in Health $(\mathrm{CH})$.

The CHQ-Parent Report Form (PF50) is a 50-item scale including 13 subscales and was completed by each child's parent or guardian, while the CHQ-Child Report Form (CF87) is a 87-item scale including 12 subscales. Each subscale is calculated by summing items and a total score of 0 to 100 ; higher scores reflect better HRQOL. This questionnaire summarizes two scales describing psychosocial (the psychosocial summary-PsS by summing psychosocial items) and physical well-being (the physical summary-PhS by summing physical items).

The questionnaire was completed within 15-20 min by direct interview with cases and controls and their care givers.

The Arabic version of the Child Health Questionnaires were not available, so the researchers translated the questionnaires to Arabic

Translation phase: First of all, we translated the questionnaires from the source language (English) into the target language (Arabic).We performed a "Jury Study "for validation of the questionnaire (Arabic Version).During the translation phase the questionnaires underwent a long process of back and forward translations, the questionnaires were reviewed by an expert panel consisting of two pediatricians and three public health experts at each session of forwardbackward translation phase. Modifications of the questionnaire were done according to the panel judgment.
Face validity: Ten children of the same age group (mainly from youngest group, low education, rural). The questionnaire was presented to them to agree about warding, meaning and understanding the questionnaire. Suggested modifications were done according to face validity.

Reliability Phase: During this phase, thirty participants fulfilling inclusionexclusion criteria were selected for assessment of the questionnaires, after signing the informed consent (pilot study).Reliability of the variables was tested using Cronbach's Alpha where it was (0.72) for CHQ-PF50 and 0.70 for CHQ-CF87.

\section{Statistical analysis:}

All statistical analyses were conducted using SPSS for windows version 16 (SPSS Inc., Chicago, IL, USA). The continuous data were expressed as mean, median and standard deviation, and were compared using Student's $\mathrm{t}$ test. Categorical variables were expressed as percentage and compared using chisquare $\left(\chi^{2}\right)$. Bivariate associations were estimated with Pearson or Spearman correlation coefficients for normally or abnormally distributed continuous variables respectively. Multivariate regression analysis was used to study the influence of independent variables on HRQOL among CHC patients. For all analyses, P-value $<0.05$ was considered statistically significant

Ethical considerations: The study protocol was approved by the ethical committee of faculty of medicine, Assiut University. The researchers assured voluntary participation and confidentiality of each child who agrees to participate in this study. Written informed consent was obtained from the caregiver for children below 12 years and from children who were more than 12 years.

\section{Results:}

\begin{tabular}{llll}
\hline The Egyptian Journal of Community Medicine & Vol. 37 & No. 1 & January
\end{tabular}


Table (1): Socio-demographic characteristics and laboratory data of the studied population, Assiut University Children Hospital, 2016

\begin{tabular}{|c|c|}
\hline & $\begin{array}{l}\text { Patients with CHC } \\
(\mathrm{N}=84)\end{array}$ \\
\hline Age (years, mean \pm SD) & $12 \pm 2.8(7-18)$ \\
\hline Sex $($ Male/Female $)(\%)$ & $64 / 20(76.2 / 23.8)$ \\
\hline Education (\%) & \\
\hline Basic & $64(76.2)$ \\
\hline Secondary & $16(19)$ \\
\hline University & $4(4.8)$ \\
\hline Residence (\%) & \\
\hline Rural & $52(61.9)$ \\
\hline Urban & $32(38.1)$ \\
\hline *Socioeconomic status (\%) & \\
\hline Low $(<15)$ & $56(66.7)$ \\
\hline Moderate (15-19) & $12(14.3)$ \\
\hline $\operatorname{High}(>19)$ & $16(19)$ \\
\hline $\begin{array}{l}\text { Duration since diagnosis } \\
\text { (months, median \& range) }\end{array}$ & $24(12.5-37)$ \\
\hline Serum albumin $(\mathrm{g} / \mathrm{dl}$, mean $\pm \mathrm{SD})$ & $3.9 \pm 0.8$ \\
\hline Serum bilirubin (ummol/l, median \& range) & $5(2.5-28.7)$ \\
\hline AST (IU/L, median \& range) & $37.5(27-143)$ \\
\hline GGT(IU/L, median \& range) & $26.5(20-150)$ \\
\hline $\mathbf{A L P}(\mathrm{IU} / \mathrm{L}$, median \& range) & $206(86-895)$ \\
\hline ALT(IU/L, median \& range) & $29(10-84)$ \\
\hline INR $($ mean \pm SD) & $1.1 \pm 0.04$ \\
\hline Hb $(\mathrm{g} / \mathrm{dl}$, mean $\pm \mathrm{SD})$ & $12.7 \pm 1.2$ \\
\hline WBC $\left(x 10^{\wedge} 3 / \mathrm{ul}\right.$, mean \pm SD $)$ & $6.8 \pm 1.8$ \\
\hline PLT $\left(x 10^{\wedge} 3 /\right.$ ul, median \& range $)$ & $265(188-458)$ \\
\hline Serum creatinine $(\mathrm{mg} / \mathrm{dl}$, mean $\pm \mathrm{SD})$ & $0.5 \pm 0.08$ \\
\hline HCV RNA (IU/L, median \& range) & $9.9 \times 10^{5}\left(2.6 \times 10^{5}-1.7 \times 10^{6}\right)$ \\
\hline
\end{tabular}

The study compromised 208 participants; $84 \mathrm{CHC}$ children and 124 controls with matched sex, age and. The mean age of CHC children was $12 \pm 2.8$ years $(7-18$ years old). The majority of those patients (76.2\%) were males, $(61.9 \%)$ from rural areas, $(76.2 \%)$ with basic education and $(66.7 \%)$ had low socioeconomic level. Socio-demographic and laboratory data of the studied patients were summarized in (Table 1).

Compared to controls, CHC patients had significantly lower mean scores of all CHQ- Child Form subscales and its 2 summaries $(\mathrm{PhS}$ and $\mathrm{PsS}, 61.56 \pm 12.01$, $64.37 \pm 13.38$ versus $78.9 \pm 8.13,77.54 \pm$ $10.52, \mathrm{P}<0.001$ for both scores respectively), except for change in health (CH) (Table 2).

In addition, apart of role functioningemotional/behavior (REB), mental health $(\mathrm{MH})$ and change in health $(\mathrm{CH}), \mathrm{CHC}$ patients had significantly lower mean scores of CHQ- Parent Form subscales and its 2 summaries than controls $(\mathrm{PhS}$ and PsS, 64.15 $\pm 16.08,64.73 \pm$ 11.57 versus $81.80 \pm 10.98,75.71 \pm$ 12.72, $\mathrm{P}<0.001$ for both scores respectively) as reported by parents (Table 3).

Among CHC children, boys had significantly impaired HRQOL than girls in the form of lower CHQ-Child Form role functioning - behavior $(\mathrm{P}=0.041)$, role functioning - physical $(\mathrm{P}=0.019)$,

\section{The Egyptian Journal of Community Medicine} 2019 
Table (2): Child-reported health-related quality of life (CHQ-Child Form) in CHC and controls, Assiut University Children Hospital,2016

\begin{tabular}{|l|l|l|l|}
\hline & \multicolumn{1}{|c|}{$\begin{array}{c}\text { CHC Patients } \\
(\mathbf{N = ~ 8 4 )}\end{array}$} & \multicolumn{1}{|c|}{$\begin{array}{c}\text { Control } \\
(\mathbf{N = 1 2 4})\end{array}$} & \multicolumn{1}{|c|}{ P-value } \\
\hline Physical functioning (FP) & $60.65 \pm 27.71$ & $95.58 \pm 11.04$ & $<0.001$ \\
\hline Role functioning- emotional (RE) & $70.89 \pm 31.87$ & $90.13 \pm 19.45$ & 0.001 \\
\hline Role functioning- behavior (RB) & $69.29 \pm 35.19$ & $87.27 \pm 25.78$ & 0.004 \\
\hline Role functioning- physical (RP) & $69.85 \pm 35.89$ & $93.01 \pm 19.94$ & $<0.001$ \\
\hline Bodily pain (BP) & $65.24 \pm 27.52$ & $84.35 \pm 14.50$ & $<0.001$ \\
\hline General behavior (BE) & $74.93 \pm 8.35$ & $80.15 \pm 12.27$ & 0.003 \\
\hline Mental health (MH) & $53.50 \pm 15.96$ & $60.03 \pm 7.11$ & 0.013 \\
\hline Self-esteem (SE) & $67.60 \pm 8.43$ & $78.69 \pm 11.93$ & $<0.001$ \\
\hline General health perceptions (GH) & $43.85 \pm 8.14$ & $52.08 \pm 7.58$ & $<0.001$ \\
\hline Change in health (CH) & $63.10 \pm 20.09$ & $59.68 \pm 23.58$ & 0.401 \\
\hline Family activities (FA) & $66.67 \pm 24.76$ & $88.71 \pm 15.56$ & $<0.001$ \\
\hline Family cohesion (FC) & $50 \pm 22.09$ & $68.95 \pm 19.49$ & $<0.001$ \\
\hline Physical summary (PhS) & $61.56 \pm 12.01$ & $78.9 \pm 8.13$ & $<0.001$ \\
\hline Psychosocial summary (PsS) & $64.37 \pm 13.38$ & $77.54 \pm 10.52$ & $<0.001$ \\
\hline
\end{tabular}

Student's $t$ test

Table (3): Comparison between cases and controls as regard Child Health

Questionnaire(CHQ-Parent Form), Assiut University Children Hospital, 2016

\begin{tabular}{|l|l|l|l|}
\hline & $\begin{array}{l}\text { CHC Patients } \\
(\mathbf{N = 8 4 )}\end{array}$ & $\begin{array}{l}\text { Control } \\
\text { (N= 124) }\end{array}$ & P-value \\
\hline Physical functioning (FP) & $69.04 \pm 28.43$ & $91.94 \pm 21.23$ & $<0.001$ \\
\hline Role functioning-emotional/behavior (REB) & $75.98 \pm 33.34$ & $84.32 \pm 26.85$ & 0.116 \\
\hline Role functioning-physical (RP) & $71.63 \pm 32.50$ & $91.25 \pm 25.10$ & 0.001 \\
\hline Bodily pain (BP) & $74.50 \pm 28.01$ & $85.50 \pm 14.72$ & 0.02 \\
\hline General behavior (BE) & $72.22 \pm 14.51$ & $81.65 \pm 15.59$ & 0.001 \\
\hline Mental health (MH) & $59.29 \pm 17.20$ & $62.34 \pm 11.99$ & 0.291 \\
\hline Parent impact-emotional (PE) & $59.52 \pm 30.72$ & $75.71 \pm 29.41$ & 0.01 \\
\hline Parent impact-time (PT) & $57.14 \pm 32.33$ & $82.66 \pm 25.74$ & $<0.001$ \\
\hline Self-esteem (SE) & $73.41 \pm 8.28$ & $83.27 \pm 11.82$ & $<0.001$ \\
\hline General health perceptions (GH) & $37.70 \pm 11.16$ & $53.28 \pm 12.57$ & $<0.001$ \\
\hline Change in health (CH) & $66.67 \pm 18.03$ & $61.29 \pm 26.55$ & 0.145 \\
\hline Family activities (FA) & $74.29 \pm 27.66$ & $95.05 \pm 27.52$ & $<0.001$ \\
\hline Family cohesion (FC) $(47.50 \pm 17.72$ & $69.76 \pm 23.49$ & $<0.001$ \\
\hline Physical summary (PhS) & $64.15 \pm 16.08$ & $81.80 \pm 10.98$ & 0.001 \\
\hline Psychosocial summary (PsS) & $64.73 \pm 11.57$ & $75.71 \pm 12.72$ & $<0.001$ \\
\hline
\end{tabular}

Student's $t$ test

bodily pain $(\mathrm{P}=0.025)$, mental health $(\mathrm{P}=$ $0.003)$, Physical summary $(\mathrm{P}=0.013)$ and psychosocial summary $(\mathrm{P}=0.013)$ (Table 4).

CHC patients with low socioeconomic status had significantly lower physical and psychosocial HRQOL (PhS; $58.84 \pm$ 11.98 and PsS; $61.63 \pm 13.23$ ) compared to moderate $(\mathrm{PhS} ; 66.74 \pm 2.78$ and $\mathrm{PsS}$; $69.80 \pm 15.92)$ and high $(\mathrm{PhS} ; 71.97 \pm$ 14.63 and $\mathrm{PsS} ; 76.56 \pm 12.40)$ socioeconomic status $(\mathrm{P}=0.02$ and 0.013 2019

respectively). However, no significant association was found between CHQ domains and other sociodemographic characteristics.

There were significant correlations between all subscales and two summary scores of CHQ-Child form and CHQParent form in CHC patients (Table 5). Also, there were significant correlations between physical summary of CHQChild Form and duration of illness, serum albumin, liver enzymes (AST and

The Egyptian Journal of Community Medicine 
Table (4): Comparison between boys and girls among patients with $\mathrm{CHC}$ as regard Child Health Questionnaire (CHQ-Child Form), Assiut University Children Hospital, 2016

\begin{tabular}{|l|l|l|r|}
\hline & $\begin{array}{l}\text { Boys with CHC } \\
\text { (N= 64) }\end{array}$ & $\begin{array}{l}\text { Girls with CHC } \\
(\mathbf{N = 2 0}\end{array}$ & P-value \\
\hline Physical functioning (FP) & $62.94 \pm 28.36$ & $53.34 \pm 25.47$ & 0.345 \\
\hline Role functioning-emotional (RE) & $66 \pm 32$ & $86.67 \pm 22.69$ & 0.072 \\
\hline Role functioning-behavior (RB) & $64.57 \pm 37.68$ & $84.40 \pm 20.48$ & 0.041 \\
\hline Role functioning-physical (RP) & $63.90 \pm 37.30$ & $88.90 \pm 23.40$ & 0.019 \\
\hline Bodily pain (BP) & $60 \pm 28.28$ & $82 \pm 16.87$ & 0.025 \\
\hline General behavior (BE) & $73.62 \pm 8.75$ & $79.12 \pm 5.32$ & 0.069 \\
\hline Mental health (MH) & $49.61 \pm 14.19$ & $65.94 \pm 15.50$ & 0.003 \\
\hline Self-esteem (SE) & $67.19 \pm 9.56$ & $68.93 \pm 2.56$ & 0.358 \\
\hline General health perceptions (GH) & $43.10 \pm 8.36$ & $46.25 \pm 7.27$ & 0.291 \\
\hline Change in health (CH) & $60.94 \pm 20.02$ & $70 \pm 19.72$ & 0.217 \\
\hline Family activities (FA) & $67.97 \pm 25.52$ & $62.50 \pm 22.91$ & 0.549 \\
\hline Family cohesion (FC) & $48.44 \pm 24.54$ & $55 \pm 10.54$ & 0.416 \\
\hline Physical summary (PhS) & $59.81 \pm 13.03$ & $67.17 \pm 5.11$ & 0.013 \\
\hline Psychosocial summary (PsS) & $61.56 \pm 13.18$ & $73.34 \pm 10$ & 0.013 \\
\hline
\end{tabular}

Student's $t$ test

Table (5): Correlations between children's $(C)$ responses and parents' $(P)$ responses on the various dimensions of the Child Health Questionnaire Assiut University Children Hospital, 2016

\begin{tabular}{|l|c|r|}
\hline & r & P \\
\hline C-FP and P-FP & 0.596 & $<0.001$ \\
\hline C-RE and P-RE & 0.494 & $<0.001$ \\
\hline C-RP and P-RP & 0.492 & $<0.001$ \\
\hline C-BP and P-BP & 0.629 & $<0001$ \\
\hline C-BE and P-BE & 0.518 & $<0.001$ \\
\hline C-MH and P-MH & 0.370 & $<0.001$ \\
\hline C-SE and P-SE & 0.202 & 0.009 \\
\hline C-GH and P-GH & 0.218 & 0.005 \\
\hline C-CH and P-CH & 0.704 & $<0.001$ \\
\hline C-FA and P-FA & 0.644 & $<0.001$ \\
\hline C-FC and P-FC & 0.431 & $<0.001$ \\
\hline C-PhS and P-PhS & 0.818 & $<0.001$ \\
\hline C-PsS and P-PsS & 0.627 & $<0.001$ \\
\hline
\end{tabular}

Pearson correlation

ALT) and platelet count. On the other hand, significant correlations were found between psychosocial summary of CHQChild Form and serum bilirubin, AST, ALP and platelet count in CHC children (Table 6).

Hypo-albuminemia was significantly associated with lower $\mathrm{PhS}$ of CHQ-Child Form $(\mathrm{P}=0.007)$. However, raised liver enzyme; ALT and low platelet count were significantly associated with impaired psychosocial summary (PsS) of CHQ-Child Form $(\mathrm{P}=0.01$ and 0.001 respectively) (Table 7).
The Egyptian Journal of Community Medicine 2019

\section{Discussion}

The effects of hepatitis c virus (HCV) infection on quality of life (QoL) are appearing as significant parameters in the evaluation of patients in last decades. Monitoring of health-related quality of life (HRQOL) is exactly reflecting the patient's illness experience or health outcome as a result of treatment. ${ }^{15}$

In this study, Child Health Questionnaires (CHQ); The CHQ-Parent Report Form (PF50) and CHQ-Child Report Form (CF87) were used for 
Table (6): Correlation between physical and psychosocial summaries and age, duration of illness and clinical and laboratory data of CHC children, Assiut University Children Hospital, 2016

\begin{tabular}{|l|l|l|l|l|}
\hline & PhS & & PsS & \\
\cline { 2 - 5 } & $\mathbf{r}$ & $\mathbf{P}$ & $\mathbf{r}$ & $\mathbf{P}$ \\
\hline *Age & 0.100 & 0.530 & 0.259 & 0.098 \\
\hline *Duration of illness & -0.351 & 0.023 & -0.226 & 0.151 \\
\hline *Serum albumin & 0.401 & 0.019 & 0.235 & 0.181 \\
\hline Serum bilirubin & -0.057 & 0.748 & -0.349 & 0.043 \\
\hline Alaninetransaminase(AST) & -0.356 & $\underline{0.046}$ & -0.324 & 0.071 \\
\hline Aspartatetransaminase(ALT) & -0.408 & $\underline{0.017}$ & -0.527 & 0.001 \\
\hline Alkalinephosphatase (ALP) & 0.176 & 0.335 & 0.469 & 0.007 \\
\hline Gammaglutamyltransferase(GGT) & -0.127 & 0.475 & -0.098 & 0.582 \\
\hline *International Normalized Ratio(INR) & -0.239 & 0.410 & -0.104 & 0.723 \\
\hline *Hemoglobin(Hb) & 0.217 & 0.206 & 0.161 & 0.363 \\
\hline *Whiteblood cells. (WBC) & 0.251 & 0.152 & -0.241 & 0.148 \\
\hline Platelet count(PLT) & 0.394 & 0.021 & 0.591 & $<0.001$ \\
\hline *Serum creatinine & -0.201 & 0.288 & -0.063 & 0.849 \\
\hline HCV RNA (IU/L) & -0.124 & 0.654 & -0.131 & 0.668 \\
\hline
\end{tabular}

*Pearson or,Spearman correlation coefficients for normally or abnormally distributed continuous variables respectively

Table (7): Multivariate regression analysis of risk factors affecting $\mathrm{CHQ}$ scores in patients with chronic hepatitis $\mathrm{C}$, Assiut University Children Hospital, 2016

\begin{tabular}{|c|c|c|c|c|}
\hline & PhS & \multirow[b]{2}{*}{$\mathbf{P}$} & \multicolumn{2}{|l|}{ PsS } \\
\hline & $\begin{array}{c}\text { Odds ratio } \\
\text { CI })\end{array}$ & & $\begin{array}{l}\text { Odds ratio }(95 \% \\
\text { CI) }\end{array}$ & $\mathbf{P}$ \\
\hline Sex & $0.4(0.2-1.7)$ & 0.564 & $0.1(0.02-3.6)$ & 0.458 \\
\hline Socioeconomic status & $0.6(0.1-1.4)$ & 0.112 & $0.6(0.1-1.2)$ & 0.075 \\
\hline Duration & $0.1(0.02-5.8)$ & 0.580 & - & \\
\hline Serum albumin & $8.9(2.6-15.2)$ & 0.007 & - & \\
\hline Serum bilirubin & - & & $-0.5(-0.9-0.1)$ & 0.071 \\
\hline AST & $-0.1(-0.3-0.2)$ & 0.211 & - & \\
\hline ALT & $-0.2(-0.4-0.5)$ & 0.175 & $-0.3(-0.4-0.4)$ & 0.01 \\
\hline ALP & - & & $0.1(0.03-0.2)$ & 0.558 \\
\hline PLT & $0.1(0.08-0.5)$ & 0.654 & $-0.1(-0.2-0.1)$ & 0.001 \\
\hline $\mathbf{R}^{2}$ & $72.6 \%$ & & $75.7 \%$ & \\
\hline \multicolumn{2}{|c|}{$\begin{array}{l}\text { CHC children in comparison with } \\
\text { healthy persons, where, scores of } \\
\text { physical and psychosocial domains of } \\
\text { CHQ (Child and Parent forms) were } \\
\text { significantly reduced in those patients } \\
\text { than controls. These results were in } \\
\text { agreement with Nydegger et al., }{ }^{16} \text { and }\end{array}$} & \multicolumn{2}{|c|}{$\begin{array}{l}\text { This impairment of HRQOL in CHC can } \\
\text { be explained by the fact that illness } \\
\text { places a heavy burden on different } \\
\text { aspects of their health, which changes } \\
\text { their attitude towards life. Hepatitis C } \\
\text { may reduce HRQOL through several } \\
\text { mechanisms. Commonly reported }\end{array}$} & $\begin{array}{l}\text { mpared } \\
\text { HC can } \\
\text { illness } \\
\text { ifferent } \\
\text { hanges } \\
\text { titis C } \\
\text { several } \\
\text { eported } \\
\text { ss may } \\
\text { crease. } \\
\text { hepatic } \\
\text { HCV. } \\
\text { ed that } \\
\text { ed }\end{array}$ \\
\hline
\end{tabular}


diagnosis of hepatitis $\mathrm{C}$ raised concern and fear about current and future health status resulting in a lower HRQOL.

Disclosure of its diagnosis may disrupt the social life owing to the fear of transmitting this disease to others or from social shame. ${ }^{24}$

On the other hand, HCV may impair HRQOL even in the absence of advanced liver disease or treatment status. ${ }^{25}$ This may be caused by neurocognitive dysfunction e.g. imapired attention, concentration, and working memory that may be attributed by HCV per se through either direct infection of the central nervous system or an indirect manner through immune response by releasing cytokines and chemokines. ${ }^{26,27}$ Furthermore, Hepatitis C virus is reported to replicate within nervous system tissues causing neuropsychiatric dysfunction. $^{28}$

The present study revealed significant correlation between children's and parents' responses on both physical and psychosocial CHQ domains. This result supports the validity of the CHQ, the same significant correlation reported by Tehranian et al. ${ }^{\mathbf{1 9}}$

Consistence with previous studies ${ }^{1,20}$, we found that boys had impaired HRQOL compared to girls $(\mathrm{P}=0.013$ for $\mathrm{PhS}$ and PsS). In contrary, Metwally et al., ${ }^{21}$ reported that female patients had significant lower mean score in comparison to males as regards total QOL. On the other hand, Tehranian et al., ${ }^{19}$ reported that no significant difference between boys and girls of chronic liver disease. The difference could be due to different age group of studied patient and different tool for HRQOL assessment used.

In the present study, $\mathrm{CHC}$ patients with lower socioeconomic status had poor physical and psychosocial HRQOL that was compatible with Thumboo et al., ${ }^{29}$ who reported that people with lower socioeconomic status had more stress, more depression, interfamilial relationship problems in their life and unaffordable appropriate treatment. Schwarzinger et al., ${ }^{30}$ found that the presence of financial burden can lower HRQOL in several areas of the SF-36 and chronic liver disease questionnaire (CLDQ).

The present study revealed that deterioration of liver function; hypoalbuminemia and raised ALT and thrombocytopenia associated with impaired physical and psychosocial HRQOL in CHC children respectively. Zuberi et al., ${ }^{31}$ reported health related CLDQ scores correlated with the severity of liver disease. Unlike our findings, several studies reported that the ALT levels were not related to HRQOL. ${ }^{30,32}$ The explanation may be due to using different questionnaires and different population groups. On the other hand, compatible with previous studies, HRQOL of CHC children was not related to age, gender and level of education. $.33,34$

\section{Conclusion and recommendations:}

It was concluded that $\mathrm{CHC}$ children had impaired HRQOL than healthy controls. hypoalbuminemia and raised ALT and thrombocytopenia were predictors of impaired physical and psychosocial HRQOL respectively.

It was recommended that increase awareness about HCV related issues with special focus on quality of life that is a significant factor when making decisions about hepatitis $\mathrm{C}$ treatment strategies. Medical and social support services should be available to children with HCV. In addition, further multicenter studies would be required to assess the neuropsychiatric state of $\mathrm{CHC}$ children and its association with HRQOL and to assess the impact of the direct acting antiviral drugs on HRQOL. 


\section{References}

1. Dalgard O, Egeland A, Skaug K, Vilimas $\mathrm{K}$, Steen T. Health-related quality of life in active injecting drug users with and without chronic hepatitis $\mathrm{C}$ virus infection. Hepatology. 2004;39(1):74-80.

2. Mack CL, Gonzalez-Peralta RP, Gupta N, Leung D, Narkewicz MR, Roberts EA, et al. NASPGHAN Practice guidelines: Diagnosis and management of hepatitis $\mathrm{c}$ infection in infants, children, and adolescents. J Pediatr Gastroenterol Nutr. 2012;54(6):838-55.

3. Delgado-Borrego A, Smith L, Jonas MM, Hall CA, Negre B, Jordan SH, et al. Expected and actual case ascertainment and treatment rates for children infected with hepatitis C in Florida and the United States: epidemiologic evidence from statewide and nationwide surveys. J Pediatr. 2012;161(5):915-21.

4. Raynes-Greenow C, Polis S, Elliott E, Hardikar W, Kesson A, Kaldor J, et al. Childhood hepatitis C virus infection: An Australian national surveillance study of incident cases over five years. J Paediatr Child Health. 2015;51(11):1115-20.

5. Behairy OGA. Health-related quality of life in children with chronic hepatitis C. Egypt Pediatr Assoc Gaz [Internet]. Egyptian Pediatric Association; 2016;64(3):120-5. https://doi.org/10.1016/j.epag.2016.08.001

6. Younossi Z, Kallman J, Kincaid J. The effects of $\mathrm{HCV}$ infection and management on health-related quality of life. Hepatology. 2007;45(3):806-16.

7. Kallman J, O'Neil MM, Larive B, Boparai N, Calabrese L, Younossi ZM. Fatigue and health-related quality of life (HRQL) in chronic hepatitis $\mathrm{C}$ virus infection. Dig Dis Sci. 2007;52(10):2531-9.

8. Lim JK, Cronkite R, Goldstein MK, Cheung RC. The impact of chronic hepatitis $\mathrm{C}$ and comorbid psychiatric illnesses on health-related quality of life. J Clin Gastroenterol. 2006;40(6):528-34

9. Spiegel BMR, Younossi ZM, Hays RD, Revicki D, Robbins S, Kanwal F. Impact of hepatitis $\mathrm{C}$ on health related quality of life: A systematic review and quantitative assessment. Hepatology. 2005;41(4):790800.
10. Forton DM, Thomas HC, Murphy $\mathrm{C}$ a., Allsop JM, Foster GR, Main J, et al. Hepatitis $\mathrm{C}$ and cognitive impairment in a cohort of patients with mild liver disease. Hepatology. 2002;35(2):433-9.

11. Hilsabeck RC, Hassanein TI, Carlson MD, Ziegler E a, Perry W. Cognitive functioning and psychiatric symptomatology in patients with chronic hepatitis C. J Int Neuropsychol Soc. 2003;9(6):847-54.

12. Goulding C, O'Connell P, Murray FE. Prevalence of fibromyalgia, anxiety and depression in chronic hepatitis $\mathrm{C}$ virus infection: relationship to RT-PCR status and mode of acquisition. Eur J Gastroenterol Hepatol. 2001;13(5):507-11.

13. Fahmy SI,EL-Sherbini AF. Determining simple parameters for social classifications for health research. Bull High Inst Public Heal. 1983;13(5):95-100.

14. HealthActCHQ. CHQ: Child Health Questionnaire. 2013; Available from: https://www.healthactchq.com/chq.php

15. Testa MA, Simonson DC. Assessment of Quality-of-Life Outcomes. N Engl J Med. 1996;334(13):835-40.

16. Nydegger A, Srivastava A, Wake M, Smith AL, Hardikar W. Health-related quality of life in children with hepatitis $\mathrm{C}$ acquired in the first year of life. $\mathrm{J}$ Gastroenterol Hepatol. 2008;23(2):226-30.

17. Schwarzenberg SJ, Ling SC, Cloonan YK, Ling H-HS, Evon DM, Murray KF, et al. Health-related quality of life in pediatric patients with chronic hepatitis B living in the United States and Canada. J Pediatr Gastroenterol Nutr. 2017;64(5):760-9.

18. El Khoury AC, Vietri J, Prajapati G. Health-related quality of life in patients with hepatitis C virus infection in Brazil. Rev Panam Salud Publica. 2014;35(3):200-6.

19. Tehranian S, Jafari S, Yousofi J, Kiani M, Seyedin S, Khakshour A, et al. Healthrelated quality of life (HRQOL) in children with chronic liver disease in North East Iran using PedsQL 4.0. Electron physician. 2015;7(4):1214-9.

20. Malhotra P, Malhotra N, Malhotra V, Chugh A, Singh I, Chaturvedi A, et al. Impact of Hepatitis C on Quality of Life. Adv Res Gastroentero Hepatol. 2016;1(4): 555569.

DOI:

\begin{tabular}{llll}
\hline The Egyptian Journal of Community Medicine & Vol. 37 & No. 1 & January \\
2019 & & &
\end{tabular}


21. Metwally AM, Abdel-Latif GA, Fouad WA, Rabah TM, Mohsen A, Shaaban FA, et al. Impact of Hepatitis $C$ Virus Chronic Infection on Quality of Life in Egypt. International Scholarly and Scientific Research \& Innovation. 2013;:7(12),848-54 urn:dai:10.1999/1307-6892/9996784

22. Nocente R, Ceccanti M, Bertazzoni G, Cammarota G, Silveri NG, Gasbarrini G. $\mathrm{HCV}$ infection and extrahepatic manifestations. 2003;50(52):1149-54.

23. Posthouwer D, Plug I, Van Der Bom JG, Fischer K, Rosendaal FR, MauserBunschoten EP. Hepatitis C and healthrelated quality of life among patients with hemophilia. Haematologica. 2005;90(6):84650.

24. Minuk GY, Gutkin A, Wong SG, Kaita KDE. Patient concerns regarding chronic hepatitis C infections. J Viral Hepat. 2005;12(1):51-7.

25. Pojoga C, Dumitra??cu DL, Pascu O, Grigorescu M, Radu C, Damian D. Impaired health-related quality of life in Romanian patients with chronic viral hepatitis before antiviral therapy. Eur $\mathbf{J}$ Gastroenterol Hepatol. 2004;16(1):27-31.

26. Morgan EE, Woods SP, Rooney A, Perry W, Grant I, Letendre SL, et al. Intraindividual variability across neurocognitive domains in chronic hepatitis $\mathrm{C}$ infection: elevated dispersion is associated with serostatus and unemployment risk. Clin Neuropsychol 2012;26(4):654-74.

27. Zampino R, Marrone A, Restivo L, Guerrera B, Sellitto A, Rinaldi L, et al. Chronic HCV infection and inflammation: clinical impact on hepatic and extra-hepatic manifestations. World J Hepatol 2013;5(10):528-40.
28. Laskus T, Radkowski M, Adair DM, Wilkinson J, Scheck AC, Rakela J. Emerging evidence of hepatitis $C$ virus neuroinvasion. Aids [Internet]. 2005;19(Suppl 3):S140-4.

29. Thumboo J, Fong KY, Machin D, Chan $\mathrm{SP}$, Soh $\mathrm{CH}$, Leong KH, et al. Quality of life in an urban Asian population: the impact of ethnicity and socio-economic status. Soc Sci Med. 2003;56(8):1761-72.

30. Schwarzinger M, Dewedar S, Rekacewicz C, Abd Elaziz KM, Fontanet A, Carrat F, et al. Chronic hepatitis $\mathrm{C}$ virus infection: does it really impact health-related quality of life? A study in rural Egypt. Hepatology. 2004; 40:1434-41

31. Zuberi BF, Memon AR, Afsar S, Qadeer R, Kumar R. Correlation of quality of life in patients of cirrhosis of liver with etiology and disease severity using disease-specific quality of life questionnaire. J Ayub Med Coll Abbottabad. 2007;19(2):7-11.

32. Batista-Neves S, Quarantini L, Galvãode Almeida A, Maurício C, Lacerda A, Paraná R, et al. Impact of Psychiatric Disorders on the Quality of Life of Brazilian HCV-Infected Patients. The Brazilian Journal of Infectious Diseases. 2009;13(1):40-3.

33. Chong CA, Gulamhussein A, Heathcote AJ, Lilly L, Sherman M, Naglie G, et al. Health-state utilities and quality of life in hepatitis C patients. Am Gastroenterol, 2003:98(3):630-8.

34. Hauser W, Holtmann G, Grandt D. Determinants of health-related quality of life in patients with chronic liver diseases. Clin Gastroenterol Hepatol. 2004; (2):157-63

The Egyptian Journal of Community Medicine
2019

